\title{
Hesitancy towards the COVID-
}

\section{9 vaccine among health care practitioners in the Kingdom}

\section{of Saudi Arabia: a cross-sectional study [version 1; peer}

\section{review: 1 approved with reservations, 1 not approved]}

\author{
Abdullah A. Almojaibel(D1, Khalid Ansari (D1, Yahya A. Alzahrani1, \\ Saleh A. Alessy (1D)2, Faraz A. Farooqi (iD) 3 , Yousef D. Alqurashi ${ }^{1}$ \\ ${ }^{1}$ Respiratory Care Department, Imam Abdulrahman Bin Faisal University, Dammam, Saudi Arabia \\ ${ }^{2}$ Department of Public Health, Saudi Electronic University, Riyadh, Saudi Arabia \\ ${ }^{3}$ College of Dentistry, Imam Abdulrahman Bin Faisal University, Dammam, Saudi Arabia
}

V1 First published: 11 Jan 2022, 11:24

https://doi.org/10.12688/f1000research.74575.1

Second version: 28 Nov 2022, 11:24

https://doi.org/10.12688/f1000research.74575.2

Third version: 09 Mar 2023, 11:24

https://doi.org/10.12688/f1000research.74575.3

Fourth version: 27 Mar 2023, 11:24

https://doi.org/10.12688/f1000research.74575.4

Latest published: $13 \mathrm{Apr} 2023,11: 24$

https://doi.org/10.12688/f1000research.74575.5

\section{Abstract}

Background: The coronavirus disease 2019 (COVID-19) pandemic is a major public health crisis worldwide. In less than 12 months since the World Health Organization declared the outbreak, several different COVID-19 vaccines have been approved and deployed mostly in developed countries since January 2021. However, hesitancy to accept the newly developed vaccines is a well-known public health challenge that needs to be addressed. The aim of this study was to measure willingness and hesitancy toward COVID-19 vaccines among health care practitioners' (HCPs) in Saudi Arabia.

Methods: A cross-sectional study using an online self-reported survey was conducted among HCPs in Saudi Arabia

between April 4th to April 25th 2021 using snowball sampling. Multivariate logistic regression was employed to identify the possible factors affecting HCPs' willingness and hesitancy to receive COVID-19 vaccines.

Results: Out of 776 participants who started the survey, 505 (65\%) completed it and were included in the results. Among all HCPs, 47 (9.3\%) either said "no" to receive the vaccine [20 (4\%)] or were hesitant to receive it [27 (5.3\%)]. Of the total number of the HCPs, 376 (74.5\%) already received the COVID-19 vaccine, and 48 (9.50\%) were

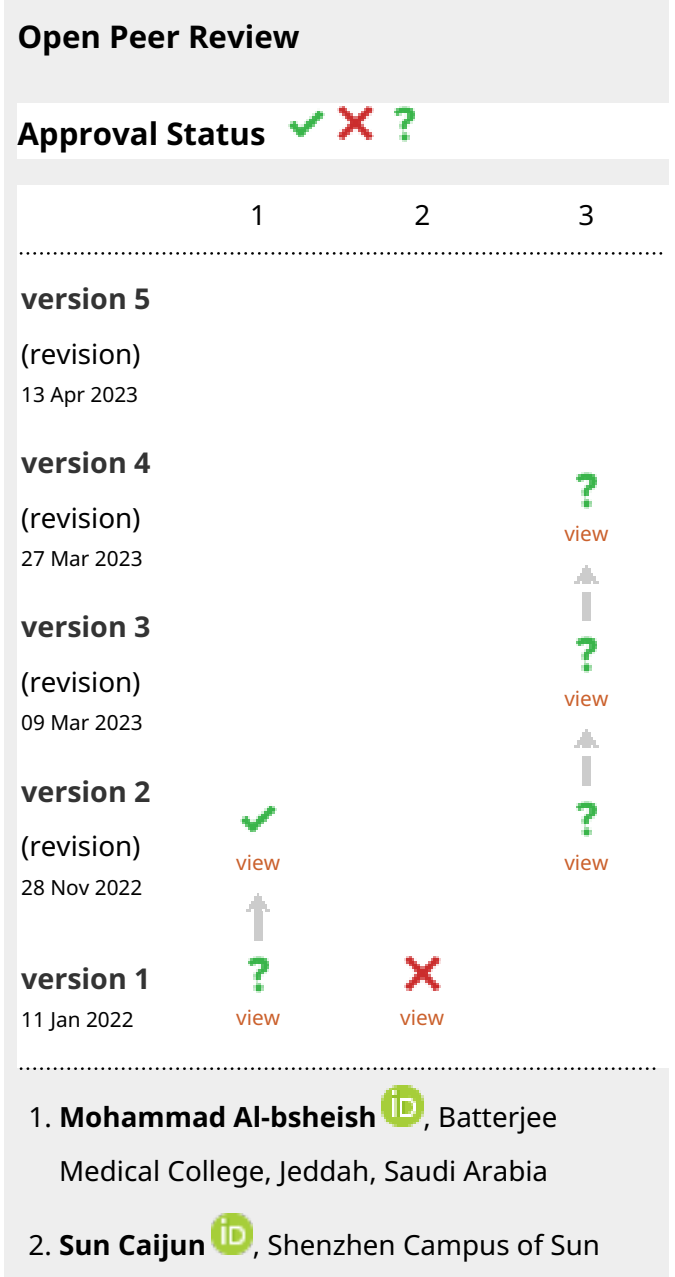


registered to receive it. The main reason of agreement to receive the COVID-19 vaccine was "wanting to protect self and others from getting the infection" (24\%).

Conclusion: Our findings have shown that hesitancy toward receiving COVID-19 vaccines among HCPs in Saudi Arabia is limited and therefore may not be a serious issue. The outcomes of this study may help to understand factors that lead to vaccine hesitancy in Saudi Arabia and help public health authorities to design targeted health education interventions aiming to increase uptake of these vaccines.

Keywords

vaccine acceptance, COVID-19 vaccine, coronavirus, Saudi Arabia, vaccine hesitancy

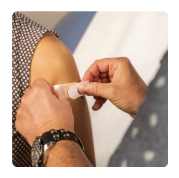

This article is included in the Sociology of Health gateway.

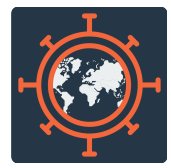

This article is included in the Emerging Diseases and Outbreaks gateway.

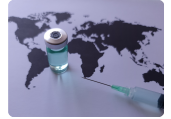

This article is included in the Sociology of

Vaccines collection.
Yat-sen University, Shenzhen, China

3. Ali Azeez Al-Jumaili (iD), Shenzhen Campus of Sun Yat-sen University, Shenzhen, China

Any reports and responses or comments on the article can be found at the end of the article.

\footnotetext{
Corresponding author: Abdullah A. Almojaibel (amojaibel@iau.edu.sa)
}

Author roles: Almojaibel AA: Conceptualization, Methodology, Project Administration, Supervision, Validation, Writing - Original Draft Preparation, Writing - Review \& Editing; Ansari K: Investigation, Validation, Writing - Original Draft Preparation; Alzahrani YA:

Methodology, Writing - Original Draft Preparation; Alessy SA: Investigation, Methodology, Writing - Original Draft Preparation; Farooqi FA: Formal Analysis, Investigation, Writing - Original Draft Preparation; Alqurashi YD: Conceptualization, Investigation, Validation, Writing - Original Draft Preparation, Writing - Review \& Editing

Competing interests: No competing interests were disclosed.

Grant information: The author(s) declared that no grants were involved in supporting this work.

Copyright: (c) 2022 Almojaibel AA et al. This is an open access article distributed under the terms of the Creative Commons Attribution License, which permits unrestricted use, distribution, and reproduction in any medium, provided the original work is properly cited. Data associated with the article are available under the terms of the Creative Commons Zero "No rights reserved" data waiver (CC0 1.0 Public domain dedication).

How to cite this article: Almojaibel AA, Ansari K, Alzahrani YA et al. Hesitancy towards the COVID-

19 vaccine among health care practitioners in the Kingdom of Saudi Arabia: a cross-sectional study [version 1; peer review: 1 approved with reservations, 1 not approved] F1000Research 2022, 11:24 https://doi.org/10.12688/f1000research.74575.1

First published: 11 Jan 2022, 11:24 https://doi.org/10.12688/f1000research.74575.1 


\section{Introduction}

The coronavirus disease 2019 (COVID-19) pandemic is a major public health concern worldwide. Since the beginning of the COVID-19 pandemic, over 236 million confirmed incidences and over 4.8 million deaths were registered worldwide. ${ }^{1}$ In less than 12 months since the World Health Organization (WHO) declared the outbreak, several numbers of COVID-19 vaccines have been approved and deployed mostly in developed countries since January 2021. In the Kingdom of Saudi Arabia (KSA), four vaccines have been approved by the health regulatory bodies (i.e., OxfordAstraZeneca, Johnson \& Johnson's Janssen, Moderna, and Pfizer/BioNTech), ${ }^{2}$ with a priority to vaccinate health care practitioners (HCPs) alongside other groups who are at a higher risk of COVID-19. ${ }^{3}$

Achieving a high vaccination coverage level among HCPs across KSA will ensure the presence of an adequate number of protected workforces to deal with the pandemic more effectively and efficiently. ${ }^{4}$ However, hesitancy to accept the newly developed vaccine is a well-known public health challenge, ${ }^{5}$ which might be exaggerated after documenting rare thromboembolic events among vaccinated individuals. ${ }^{6}$

Arguably, several studies have sought to determine the level of willingness to receive the vaccine as well as the factors influencing vaccine acceptance. ${ }^{7,8}$ To examine this further, a study was conducted recently in KSA prior to the development of the vaccines, demonstrated that only $50 \%$ of the HCPs were willing to receive the vaccine. ${ }^{9}$ In addition, another study carried out in the United States showed that concerns about vaccine efficacy, adverse effects, and rapidity of the production were the most important factors affecting hesitancy or reluctance to receive the COVID-19 vaccine. ${ }^{10}$

There has been no research conducted after the approval of the COVID-19 vaccines in KSA. Therefore, this study aimed to measure willingness and hesitancy toward COVID-19 vaccines among HCPs in Saudi Arabia.

\section{Methods}

\section{Design}

We conducted a cross-sectional study to assess willingness and hesitancy toward COVID-19 vaccines among HCPs in KSA. We created an online self-reported survey using the Question Pro survey tool hosted at Imam Abdulrahman Bin Faisal University (IAU). The survey was offered only in English because most of the HCPs in Saudi speak and understand English. The questions asked in the survey are available as part of the underlying data. ${ }^{26}$ Responses were collected anonymously and no personally identifying information was collected. This study was approved by the IAU's Institutional Review Board (IRB-2021-03-149).

\section{Sampling}

We utilized convenience sampling method to recruit participants. The survey was distributed via online links posted on social media platforms (e.g., Twitter, LinkedIn, and WhatsApp) to reach responses from various HCPs groups in KSA. Participants were encouraged to further distribute the survey among other HCPs groups. Data were collected from April $4^{\text {th }}$ to April $25^{\text {th }} 2021$.

\section{Participants}

All adults (>18 years of age) currently working in healthcare facilities in KSA, regardless of the level of patient contact and their clinical role, were eligible to participate in the study. Informed consent was obtained from all the participants prior to starting the survey. A participation consent statement was added on the study information page as follows: "If you are a health care practitioner in Saudi Arabia and consent to participate in this survey, please proceed to the next page to start the survey." Only those who agreed to participate where allowed to complete the survey. Proceeding to the survey page was therefore taken as consent to participate.

\section{Measures}

The survey collected participants' demographics and health information and assessed HCPs' attitude and perception of COVID-19 and COVID-19 vaccines. Furthermore, the survey assessed the HCPs' willingness to receive COVID-19 vaccines as well as hesitancy level as measured by the vaccine hesitancy scale (VHS). The VHS includes 10 items measured on a 5-point Likert scale ranging from strongly disagree to strongly agree. The VHS is developed by the WHO Strategic Advisory Group of Experts (SAGE) to capture parental attitudes, beliefs, and behaviors surrounding vaccination. ${ }^{11}$ The COVID-19 vaccines hesitancy scale, ${ }^{7}$ which was adopted in this study, is a modified version of the VHS. The validity and reliability of the COVID-19 VHS was established in another study. ${ }^{7}$ However, we piloted the survey with nine HCPs currently practicing in KSA to assure the clarity of the questions and to evaluate the face and content validity of the scale on the targeted population. 
Table 1. Sociodemographic characteristics of the study participants $(n=505)$.

\begin{tabular}{|c|c|c|}
\hline \multicolumn{2}{|l|}{ Demographic variables } & \multirow{2}{*}{$\begin{array}{l}\text { Number (\%) } \\
259(51.3)\end{array}$} \\
\hline Gender & Male & \\
\hline & Female & $246(48.7)$ \\
\hline \multirow[t]{2}{*}{ Nationality } & Saudi & $438(86.7)$ \\
\hline & Non-Saudi & $67(13.3)$ \\
\hline \multirow[t]{8}{*}{ Age } & $18-24$ & $152(30.1)$ \\
\hline & $25-29$ & $98(19.4)$ \\
\hline & $30-34$ & $70(13.9)$ \\
\hline & $35-39$ & $82(16.2)$ \\
\hline & $40-44$ & $45(8.9)$ \\
\hline & $45-49$ & $24(4.8)$ \\
\hline & $50-54$ & $21(4.2)$ \\
\hline & more than 54 & $13(2.6)$ \\
\hline \multirow{5}{*}{$\begin{array}{l}\text { Residency province in } \\
\text { Kingdom of Saudi Arabia }\end{array}$} & West & $44(8.7)$ \\
\hline & Central & $102(20.2)$ \\
\hline & Eastern & $345(68.3)$ \\
\hline & South & $10(2)$ \\
\hline & Northern & $4(0.8)$ \\
\hline \multirow[t]{6}{*}{ Health profession } & Physician & $89(17.6)$ \\
\hline & Nurse & $61(12.1)$ \\
\hline & Dentist & $12(2.4)$ \\
\hline & Pharmacist & $28(5.5)$ \\
\hline & $\begin{array}{l}\text { Other Health Care Specialists (respiratory therapy, } \\
\text { physiotherapy, clinical nutrition, etc.) }\end{array}$ & $289(57.2)$ \\
\hline & Technician in allied medical sciences & $26(5.1)$ \\
\hline \multirow[t]{5}{*}{ Current state of health } & Excellent & $246(48.7)$ \\
\hline & Very good & $173(34.3)$ \\
\hline & Good & 75 (14.9) \\
\hline & Fair & $10(2)$ \\
\hline & Bad & $1(0.2)$ \\
\hline \multirow[t]{2}{*}{ Having chronic diseases } & Yes & $88(17.4)$ \\
\hline & No & $417(82.6)$ \\
\hline \multirow[t]{2}{*}{ Infected with COVID-19 } & Yes & $86(17)$ \\
\hline & No & $419(83)$ \\
\hline \multirow{2}{*}{$\begin{array}{l}\text { Family member infected } \\
\text { with COVID-19 }\end{array}$} & Yes & $424(84)$ \\
\hline & No & $81(16)$ \\
\hline \multirow[t]{3}{*}{ Received COVID-19 vaccine } & Yes & $376(74.5)$ \\
\hline & I have registered & $48(9.5)$ \\
\hline & No & $81(16)$ \\
\hline \multirow{3}{*}{$\begin{array}{l}\text { Would you like to receive } \\
\text { COVID-19 vaccine? }\end{array}$} & Yes, I would like to & $34(6.7)$ \\
\hline & I would be hesitant & $27(5.3)$ \\
\hline & No, I would refuse & $20(4)$ \\
\hline \multirow{3}{*}{$\begin{array}{l}\text { Preferable vaccine to } \\
\text { receive }\end{array}$} & Pfizer & $20(59)$ \\
\hline & AstraZeneca & $2(6)$ \\
\hline & No Preference & $12(35)$ \\
\hline
\end{tabular}




\section{Statistical analysis}

For descriptive analyses, univariate analyses were used to evaluate the associations between HCPs' willingness to receive COVID-19 vaccines and their demographic characteristics, awareness, and health status. The differences in the VHS between participants who reported their willingness to receive the vaccine and those who had no intention to receive the vaccine were determined by $t$ tests. Subsequently, we employed multivariate logistic regression to identify the possible factors affecting HCPs' willingness to receive the COVID-19 vaccines. Based on multiple previous studies that explored vaccines' acceptance, ${ }^{8,9,12}$ several sociodemographic factors (e.g., age, residency province, and health profession), health status, and perception of COVID-19 and COVID-19 vaccines were included in the multivariable regression model. For the above regression, odds ratio (OR) and the respective 95\% CI were estimated. All analyses were performed using SPSS 26.0 (IBM Corporation, New York, NY, United States). The level of statistical significance was set at $p<0.05$ for this analysis.

\section{Results}

Out of 776 participants who started the survey, 505 (65.1\%) completed it and were included in the analysis. The remaining 271 did not complete the survey fully; therefore, they were excluded. The demographical characteristics of the

Table 2. Associations between the sociodemographic characteristics of health care professionals and willingness to receive the COVID-19 vaccines.

\begin{tabular}{|c|c|c|c|c|c|}
\hline \multicolumn{2}{|l|}{ Variables } & \multirow{2}{*}{$\begin{array}{l}\text { Agree } \\
\mathbf{n}=387 \\
32.3 \%\end{array}$} & \multirow{2}{*}{$\begin{array}{l}\text { Not sure } \\
\mathbf{n}=86 \\
25.6 \%\end{array}$} & \multirow{2}{*}{$\begin{array}{l}\text { Disagree } \\
\mathbf{n}=\mathbf{3 2} \\
15.6 \%\end{array}$} & \multirow{2}{*}{$\begin{array}{l}\text { p-values } \\
0.30\end{array}$} \\
\hline Age & $18-24$ & & & & \\
\hline & $25-29$ & $18.1 \%$ & $24.4 \%$ & $21.9 \%$ & \\
\hline & $30-34$ & $13.7 \%$ & $12.8 \%$ & $18.8 \%$ & \\
\hline & $35-39$ & $15.8 \%$ & $16.3 \%$ & $21.9 \%$ & \\
\hline & $40-44$ & $9.3 \%$ & $4.7 \%$ & $15.6 \%$ & \\
\hline & $45-49$ & $4.9 \%$ & $4.7 \%$ & $3.1 \%$ & \\
\hline & $50-54$ & $4.1 \%$ & $5.8 \%$ & $0.0 \%$ & \\
\hline & more than 54 & $1.8 \%$ & $5.8 \%$ & $3.1 \%$ & \\
\hline \multirow[t]{2}{*}{ Gender } & Male & $52.7 \%$ & $43.0 \%$ & $56.3 \%$ & \multirow[t]{2}{*}{0.26} \\
\hline & Female & $47.3 \%$ & $57.0 \%$ & $43.8 \%$ & \\
\hline \multirow[t]{2}{*}{ Nationality } & Saudi & $85.8 \%$ & $91.9 \%$ & $84.4 \%$ & \multirow[t]{2}{*}{0.30} \\
\hline & Non-Saudi & $14.2 \%$ & $8.1 \%$ & $15.6 \%$ & \\
\hline \multirow[t]{6}{*}{ Health profession } & Physician & $17.3 \%$ & $16.3 \%$ & $25.0 \%$ & \multirow[t]{6}{*}{0.13} \\
\hline & Nurse & $10.3 \%$ & $16.3 \%$ & $21.9 \%$ & \\
\hline & Dentist & $2.6 \%$ & $2.3 \%$ & $0.0 \%$ & \\
\hline & Pharmacist & $4.4 \%$ & $8.1 \%$ & $12.5 \%$ & \\
\hline & Other Health Care Specialists & $60.2 \%$ & $51.2 \%$ & $37.5 \%$ & \\
\hline & $\begin{array}{l}\text { Technician in allied medical } \\
\text { sciences }\end{array}$ & $5.2 \%$ & $5.8 \%$ & $3.1 \%$ & \\
\hline \multirow{5}{*}{$\begin{array}{l}\text { Residency province in } \\
\text { Kingdom of Saudi Arabia }\end{array}$} & West & $8.5 \%$ & $9.3 \%$ & $9.4 \%$ & \multirow[t]{5}{*}{0.34} \\
\hline & Central & $18.1 \%$ & $26.7 \%$ & $28.1 \%$ & \\
\hline & Eastern & $71.1 \%$ & $59.3 \%$ & $59.4 \%$ & \\
\hline & South & $1.8 \%$ & $2.3 \%$ & $3.1 \%$ & \\
\hline & Northern & $.5 \%$ & $2.3 \%$ & $0.0 \%$ & \\
\hline \multirow[t]{4}{*}{ Current state of health } & Excellent & $48.8 \%$ & $44.2 \%$ & $59.4 \%$ & \multirow[t]{4}{*}{0.03} \\
\hline & Very good & $34.6 \%$ & $33.7 \%$ & $31.3 \%$ & \\
\hline & Good & $14.2 \%$ & $20.9 \%$ & $6.3 \%$ & \\
\hline & Fair & $2.1 \%$ & $1.2 \%$ & $3.1 \%$ & \\
\hline \multirow[t]{2}{*}{ Having chronic diseases } & Yes & $18.3 \%$ & $17.4 \%$ & $6.3 \%$ & \multirow[t]{2}{*}{0.25} \\
\hline & No & $81.7 \%$ & $82.6 \%$ & $93.8 \%$ & \\
\hline
\end{tabular}




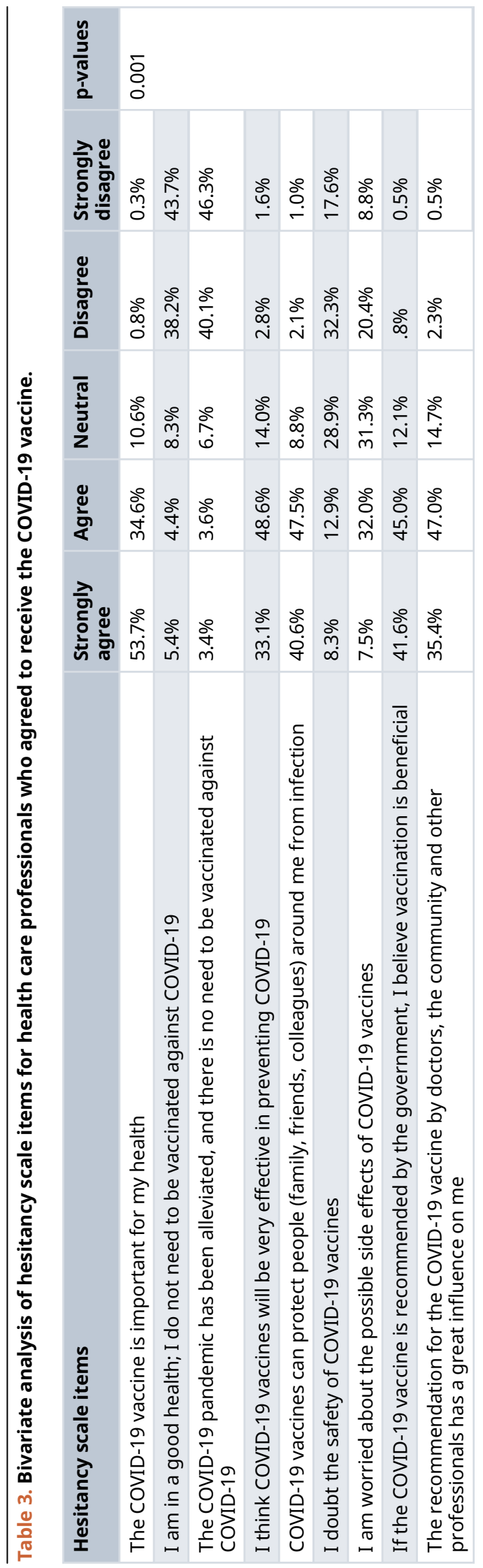


participants are presented in Table 1. Among 505 HCPs who completed the survey, 47 (9.3\%) either said "no" to receive the vaccine [20 (4\%)] or were hesitant to receive it [27 (5.3\%)]. Of the total number of the HCPs, $376(74.5 \%)$ had already received the COVID-19 vaccine, and 48 (9.5\%) were registered to receive it. Out of the 34 participants $(6.7 \%)$ who wanted to receive the vaccine, the majority of them [20 (59\%)] preferred the Pfizer-BioNTech vaccine because they believed it had fewer side effects and was more effective than AstraZeneca vaccine.

The associations between the demographic characteristics of the HCPs and their willingness to receive COVID-19 vaccines is presented in Table 2. Women were more hesitant to receive the vaccine (47.3\%) compared to men. However, no statistically significant association was found between gender and willingness to receive the vaccine $(p=0.26)$. Significant association was only found between having excellent or good health condition and the willingness to receive the COVID-19 vaccine ( $p=0.03)$.

Table 3 represents the bivariate analysis of hesitancy scale items for the HCPs who agreed to receive the COVID-19 vaccine. The majority of the participants who agreed to receive the vaccine were found to agree (53.7\%) or strongly disagree (34.6\%) that "the COVID-19 vaccine is important for my health". Also, most of the participants were found to agree $(33.1 \%)$ or strongly agree (48.6\%) that "COVID-19 vaccines will be very effective in preventing COVID-19". Only $21.2 \%$ of the HCPs doubt the safety of COVID-19 vaccines, and $28.9 \%$ were neutral about the vaccine's safety.

Figure 1 shows the reasons of accepting to receive the COVID-19 vaccine; wanting to protect self and others from getting the infection was the main reason (24\%). Figure 2, however, shows the reasons for not accepting COVID-19 vaccines. Most of the HCPs were lacking the trust in this vaccine because it is new (20\%).

\section{Discussion}

The main finding of this study was that $9.3 \%$ of the HCPs either didn't want to receive the vaccine or were hesitant to receive it. This indicates that the vaccine hesitancy among the HCPs in our sample from Saudi Arabia may not be of a serious issue. Although there are few studies assessed the hesitancy toward vaccination, our results are consistent with the current literature. ${ }^{13,14}$ Civelek et al. (2021) found that $68.4 \%$ of physicians in Turkey were willing to get vaccinated. ${ }^{13}$ Robertson et al. (2021) reported that $82 \%$ of UK population were willing to get vaccinated. ${ }^{14}$ However, willingness level to receive the vaccine may differ between countries and communities. In a recent study, sampled from 19 countries with

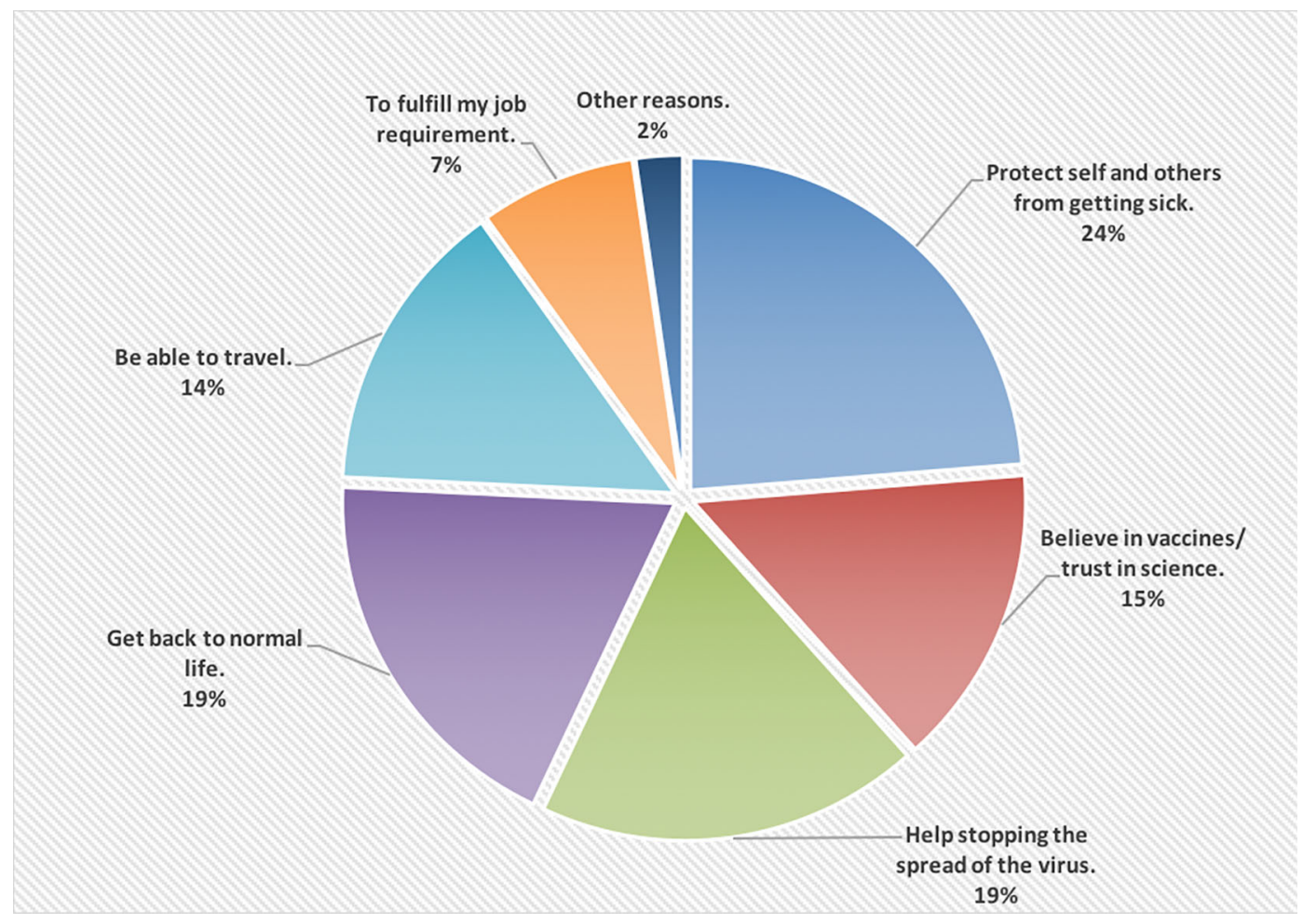

Figure 1. The main reasons of accepting to receive the COVID-19 vaccine. 


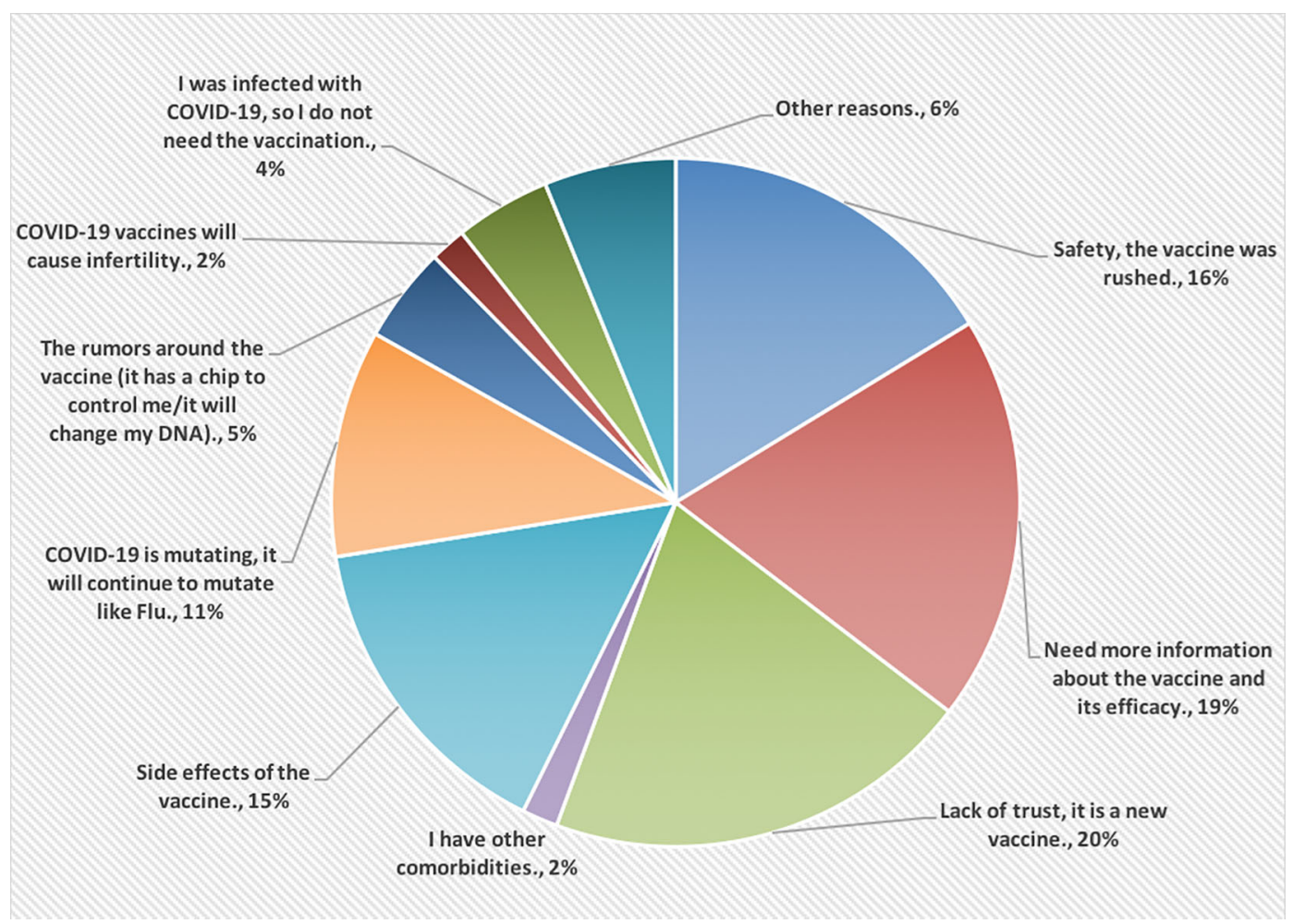

Figure 2. The main reasons for not accepting COVID-19 vaccines.

more than 13,000 participants, the acceptance of COVID-19 vaccines ranged from $54.8 \%$ in Russia to $88.6 \%$ in China. ${ }^{15}$ Data collected from Saudi Arabia before the vaccination campaign showed that the COVID-19 vaccines' acceptance level among the population was $64.7 \% .^{16}$

The results of this study showed that $76.6 \%$ of the Saudi HCPs were willing to receive COVID-19 vaccines. A previous study on HCPs in Saudi Arabia, prior to the vaccination campaign, showed that the COVID-19 vaccines' acceptance level was reported to be $50.5 \%$. $^{9}$ This surge in the acceptancy level by more than $26 \%$ following the vaccine campaign can be attributed to several factors, but one major factor was that the government of Saudi Arabia prohibited unvaccinated people from traveling, entering private establishments and government buildings, or performing Hajj and Umrah. ${ }^{17}$

Our study showed that the majority of those who agreed to receive the vaccine were young, up to 24 years. This result is similar to a study conducted by Al-Mohaithef et al. (2020) in which they found that the majority of those who agree to receive the vaccine were from the age group between 26 to $35 .{ }^{16}$ Qattan et al. in 2021 measured Saudi HCPs' acceptance of the COVID-19 vaccine and found that the majority of those who agreed to receive the vaccine were from the age group between 30 to 39 years. ${ }^{9}$ However, several other studies showed that the willingness to receive COVID-19 vaccines were higher in old ages (50 years and above) for HCPs, ${ }^{10}$ and for the general population. ${ }^{18}$ One justification for this contradiction between Saudi HCPs and others can be attributed to the youth population of Saudi Arabia compared to the western countries. In total, $37 \%$ of the Saudi population are between the age of 15 to 34 years.

Interestingly, our study results showed that the factors that influenced the HCPs willingness to receive the vaccine were:

1) Perceived their health status as excellent or very good; and

2) Believed that vaccines will relieve the pandemic.

These findings supports the conclusions of several previous studies ${ }^{20-22}$ that showed health issues such as mental illness, chronic health problems or physical health problems may lead to both vulnerability and inequality. ${ }^{20}$ Therefore, even if the vaccines uptake falls short in some high-risk groups, a trivial increase in vaccines uptake will have significant health benefits. $^{22}$ 
We also determined the reasons for accepting or rejecting to receive COVID-19 vaccines as reported by the HCPs. Our findings contradict the results from Verger et al. (2021) about the safety concerns of COVID-19 vaccines. ${ }^{8}$ Verger and colleagues concluded that concerns about the safety of the COVID-19 vaccines was, by far, the most important factor for hesitancy or reluctance and for moderate acceptance. ${ }^{8}$ Contrarily, Shekhar et al. (2021) found that most HCPs (86\%) believe that the COVID-19 vaccine is safe. However, Qattan et al. (2021) study showed that $16.82 \%$ of the HCPs in KSA have safety and efficacy concerns about COVID-19 vaccines, and 26.73\% have fear of the adverse side effects of the vaccines. ${ }^{9}$ Even though our study was conducted after the beginning of the vaccine campaigns, we found that $21 \%$ of the HCPs doubt the safety of the vaccines, and $39.5 \%$ were worried about the possible side effects of COVID-19 vaccines. The increased percentage of HCPs with concerns regarding the COVID-19 vaccines in our study could be explained by the recent reports about the possible vaccine's adverse effects, such as the formation of blood clots in large arteries. ${ }^{23}$

Previous studies suggested that believing in the conspiracy theory behind COVID-19 was a factor of rejection. ${ }^{9,24,25}$ This is similar to our findings which suggested that $5 \%$ of the HCPs rejected the vaccine because they believed rumors about the vaccines such as the "chip theory". Although 5\% seems low, it may reflect the fact that our population only included HCPs and this percentage could rise if we conducted the study in the general population and amongst those who do not trust any source of information on COVID-19 vaccines. However, Qattan et al. reported that only $0.6 \%$ of the HCPs believed that COVID-19 does not exists. ${ }^{9}$

This study has some limitations. First, although the sample size in our study was objectively determined, we used a snowball sampling method to distribute the survey link among HCPs in the KSA. This method may have caused a selection bias since most of our sample were from the eastern province of KSA. Therefore, our sample may not be representative of all HCPs in KSA, which can limit the generalizability of the findings. In addition, this was a crosssectional study. Therefore, we could not draw causal relationships between the factors and COVID-19 vaccine acceptance. Finally, the study's questionnaire was published online in the English language only, which produced a selection bias favoring English-literate HCPs only and those who have Internet connections.

Despite the limitations, our study was able to explore some of the unknown factors associated with COVID-19 vaccine acceptance and rejection which were not explored in previous studies. Also, given the representative sample size across KSA, the findings comprehensively demonstrated health care practitioners' intention to uptake the COVID-19 vaccine. Future research is therefore needed to assess this study's findings and to examine additional challenges around vaccinations in the Saudi population. Further investigations of the vaccine's safety awareness and promotion strategies to encourage individuals to get the vaccine, as well as exploring key barriers towards receiving the COVID-19 vaccination are needed.

\section{Conclusion}

Our findings have shown that hesitancy toward receiving COVID-19 vaccines among HCPs in Saudi Arabia is limited and therefore may not be of a serious issue. Also, the outcomes of this study help to understand factors that lead to vaccine hesitancy in Saudi Arabia and help public health authorities to design targeted health education interventions aiming to increase vaccine's acceptance and uptake.

\section{Data availability}

Underlying data

Harvard Dataverse: Hesitancy of COVID-19 vaccine among health care practitioners in the Kingdom of Saudi Arabia, https://doi.org/10.7910/DVN/E90NQL ${ }^{26}$

The project contains the following underlying data:

- SurveyReport-8303281-04-22-2021-T042516.666.tab (raw data from questionnaire).

Data are available under the terms of the Creative Commons Zero "No rights reserved" data waiver (CC0 1.0 Public domain dedication).

\section{Competing interests}

No competing interests were disclosed.

\section{Grant information}

The authors declare that no grants were involved in supporting this work. 
1. WHO Coronavirus (COVID-19) Dashboard|WHO Coronavirus (COVID-19) Dashboard With Vaccination Data.

Reference Source

2. E-Services - Request for Vaccine Approval in the Kingdom. Reference Source

3. MOH News - MOH Announces Priority Groups for COVID-19 Vaccination.

Reference Source

4. Alshammari TM, Yusuff KB, Aziz MM, et al.: Healthcare professionals' knowledge, attitude and acceptance of influenza vaccination in Saudi Arabia: a multicenter cross-sectional study. BMC Health Serv. Res. 2019 Apr; 19(1): 229.

PubMed Abstract | Publisher Full Text

5. Chevallier C, Hacquin A-S, Mercier H: COVID-19 Vaccine Hesitancy: Shortening the Last Mile. Trends Cogn. Sci. 2021/02/09. 2021 May; 25(5): 331-333.

PubMed Abstract | Publisher Full Text | Reference Source

6. Østergaard SD, Schmidt M, Horváth-Puhó E, et al.: Thromboembolism and the Oxford-AstraZeneca COVID-19 vaccine: side-effect or coincidence?. Lancet. 2021; 397(10283): $1441-1443$.

PubMed Abstract | Publisher Full Text

7. Chen $M, L i Y, C h e n$ J, et al.: An online survey of the attitude and willingness of Chinese adults to receive COVID-19 vaccination. Hum. Vaccin. Immunother. 2021 Jan; 17: 2279-2288. Publisher Full Text

8. Verger P, Scronias D, Dauby N, et al.: Attitudes of healthcare workers towards COVID-19 vaccination: a survey in France and French-speaking parts of Belgium and Canada, 2020. Euro Surveill Bull Eur sur les Mal Transm = Eur Commun Dis Bull. 2021 Jan; 26(3). Publisher Full Text

9. Qattan AMN, Alshareef N, Alsharqi O, et al.: Acceptability of a COVID-19 Vaccine Among Healthcare Workers in the Kingdom of Saudi Arabia. Front Med. 2021 Mar 1; 8: 644300. PubMed Abstract | Publisher Full Text | Reference Source

10. Shekhar R, Sheikh AB, Upadhyay S, et al.: CovID-19 vaccine acceptance among health care workers in the united states. Vaccines. 2021; 9(2): 1-18. Publisher Full Text

11. Larson HJ, Jarrett C, Schulz WS, et al.: Measuring vaccine hesitancy: The development of a survey tool. Vaccine. 2015; 33(34): 4165-4175.

PubMed Abstract | Publisher Full Text | Reference Source

12. Kwok KO, Li K-K, Wei WI, et al.: Influenza vaccine uptake, COVID-19 vaccination intention and vaccine hesitancy among nurses: A survey. Int. J. Nurs. Stud. 2021; 114. Publisher Full Text| PubMed Abstract | Reference Source

13. Civelek B, Yazici O, Ozdemir N, et al.: Attitudes of physicians towards COVID-19 vaccines and reasons of vaccine hesitancy in Turkey. Int. J. Clin. Pract. 2021 May; e14399.
14. Robertson E, Reeve KS, Niedzwiedz CL, et al.: Predictors of COVID19 vaccine hesitancy in the UK Household Longitudinal Study. medRxiv. 2021 Jan 1. 2020.12.27.20248899. Reference Source

15. Lazarus JV, Ratzan SC, Palayew A, et al:: Author Correction: A global survey of potential acceptance of a COVID-19 vaccine (Nature Medicine, (2021), 27, 2 (225-228), 10.1038/s41591-020-1124-9). Nat Med. 2021; 27(2): 354 PubMed Abstract | Publisher Full Text

16. Al-Mohaithef M, Padhi BK: Determinants of covid-19 vaccine acceptance in saudi arabia: A web-based national survey. J. Multidiscip. Healthc. 2020; Volume 13: 1657-1663. PubMed Abstract | Publisher Full Text

17. Saudi Arabia to require vaccination to enter governmental private establishments - SPA|Reuters. [cited 2021 Jul 2]. Reference Source

18. Malik AA, McFadden SM, Elharake J, et al.: Determinants of COVID19 vaccine acceptance in the US. EClinicalMedicine. 2020 Sep; 26 : 100495.

PubMed Abstract | Publisher Full Text

19. Saudi Arabia: population distribution by age group 2020 Statista. [cited 2021 Jul 2]. Reference Source

20. Covid-19 vaccination programme: where do people with mental health difficulties lie within the order of priority? - The BMJ. Reference Source

21. Annex A: COVID-19 vaccine and health inequalities: considerations for prioritisation and implementation - GOV.UK. Reference Source

22. Hungerford D, Vivancos R, Read JM, et al.: Rotavirus vaccine impact and socioeconomic deprivation: An interrupted time-series analysis of gastrointestinal disease outcomes across primary and secondary care in the UK. BMC Med. 2018; 16(1): 10. PubMed Abstract | Publisher Full Text

23. First reported cases of clots in large arteries causing stroke following covid-19 vaccination. BM] [cited 2021 Jul 4]. Reference Source

24. COVID-19 vaccine deployment: behaviour, ethics misinformation and policy strategies. 2020. Reference Sourc

25. Duffy B: Coronavirus: vaccine misinformation and the role of social media. Reference Source

26. Hesitancy of COVID-19 vaccine among health care practitioners in the Kingdom of Saudi Arabia.

Publisher Full Tex 


\section{Open Peer Review}

\section{Current Peer Review Status: ? $\mathrm{X}$}

\section{Version 1}

Reviewer Report 06 September 2022

https://doi.org/10.5256/f1000research.78348.r148319

(C) 2022 Caijun S. This is an open access peer review report distributed under the terms of the Creative Commons Attribution License, which permits unrestricted use, distribution, and reproduction in any medium, provided the original work is properly cited.

\section{Sun Caijun}

School of Public Health (Shenzhen), Shenzhen Campus of Sun Yat-sen University, Shenzhen, China

This manuscript mainly investigated the COVID-19 vaccine acceptance and intentions among healthcare workers in Saudi Arabia. There have been many similar investigations, so the authors should compare their work with the published data and provide explanation of possible discrepancy.

Only 505 valid participants were investigated in this survey. Please state how to calculate the minimum sample size of participants in this survey.

Please also state the inclusion and exclusion criteria for these participants in this survey. Selection bias may exist if the participants with small sample size were recruited without reasonable inclusion and exclusion criteria.

The study was conducted in April, 2021, but the pandemic situation and vaccination policies changed greatly during this year. This change always influenced people's attitudes towards COVID-19 vaccination, and therefore the conclusion might be changed.

Is the work clearly and accurately presented and does it cite the current literature? Partly

Is the study design appropriate and is the work technically sound? Partly

Are sufficient details of methods and analysis provided to allow replication by others? Partly

If applicable, is the statistical analysis and its interpretation appropriate? Partly

Are all the source data underlying the results available to ensure full reproducibility? 
Partly

Are the conclusions drawn adequately supported by the results?

Partly

Competing Interests: No competing interests were disclosed.

Reviewer Expertise: Vaccine; infectious diseases; antiviral drugs

I confirm that I have read this submission and believe that I have an appropriate level of expertise to state that I do not consider it to be of an acceptable scientific standard, for reasons outlined above.

Reviewer Report 24 January 2022

https://doi.org/10.5256/f1000research.78348.r119369

(c) 2022 Al-bsheish M. This is an open access peer review report distributed under the terms of the Creative Commons Attribution License, which permits unrestricted use, distribution, and reproduction in any medium, provided the original work is properly cited.

\section{Mohammad Al-bsheish}

Healthcare Administration Department, Batterjee Medical College, Jeddah, Saudi Arabia

Dear authors,

Thank you for your submission of your article entitled "Hesitancy towards the COVID-19 vaccine among health care practitioners in the Kingdom of Saudi Arabia: a cross-sectional study" for F1000Research.

Here are some comments for improvement. I hope these comments are useful!

Title: your study aims to measure willingness and hesitancy toward COVID-19 vaccines among health care practitioners (HCPs) in Saudi Arabia. However, "willingness" is conspicuously absent from the title; I suggest adding the willingness to the title.

\section{Introduction}

Due to massive changes in the number of cases every day, mentioning the date you got the statistics increases the accuracy for the readers.

The problem statement in the introduction needs to be enriching more by mentioning: The impact of COVID-19 on HCPs by presenting governmental statistics and previous studies

More international and national literature on hesitancy and willingness of receiving the vaccine The motive to conduct this study in particular if we consider the high percentage vaccination rate in Saudi Arabia and how the compensation mechanism of HCPs who are 
declining to receive the vaccine is affected, as they are able and trained to protect patients by using the safety compliance behaviours and adhering to PPE. Please see "Al-Bsheish, M., Jarrar, M. T., \& Scarbrough, A. (2021). A Public Safety Compliance Model of Safety Behaviors in the Age of the COVID-19 Pandemic. INQUIRY: The Journal of Health Care Organization, Methods Provision, and Financing, 58, 1-6".

In the Participant's part, you mentioned "All adults ( $>18$ years of age) currently working in healthcare facilities in KSA" while your investigation is among HCPs! ...This may confuse the readers.

In the Measures part, you wrote "we piloted the survey with nine HCPs currently practicing in KSA to assure the clarity of the questions and to evaluate the face and content validity of the scale on the targeted population", did you mean pre-test? Because you examined the face and content validity, however, the pilot study investigates the reliability of the scale by Cronbach's alpha, and the minimal size to conduct it is 30 participants. Please See "Sekaran, U., \& Bougie, R. (2016). Research methods for business: A skill-building approach. John Wiley \& Sons".

\section{Results}

You wrote "Women were more hesitant to receive the vaccine (47.3\%) compared to men". While Table 2 shows the willingness to receive the COVID-19 vaccines. There is a difference between willingness and hesitancy. I would change this to "Women were less willing to receive the vaccine".

\section{Discussion}

Well written and interesting, however, it is better to focus on the conspiracy theories in your introduction to enrich your problem statement in this study.

It is better to add the limitations and future studies in separate parts after the discussion.

Lastly, please revise the manuscript for flow and English language edits and update any references

Again, thank you for your work, and good luck.

MAG

\section{References}

1. Al-Bsheish M, Jarrar M, Scarbrough A: A Public Safety Compliance Model of Safety Behaviors in the Age of the COVID-19 Pandemic. INQUIRY: The Journal of Health Care Organization, Provision, and Financing. 2021; 58. Publisher Full Text

2. Sekaran U, Bougie R: Research Methods for Business: A Skill-Building Approach. Wiley.

Is the work clearly and accurately presented and does it cite the current literature? Yes

Is the study design appropriate and is the work technically sound? Yes

Are sufficient details of methods and analysis provided to allow replication by others? Yes

If applicable, is the statistical analysis and its interpretation appropriate? 
Yes

Are all the source data underlying the results available to ensure full reproducibility? Yes

Are the conclusions drawn adequately supported by the results?

Yes

Competing Interests: No competing interests were disclosed.

Reviewer Expertise: Healthcare Administration, Occupational Safety and Quality Management, Nursing Science

I confirm that I have read this submission and believe that I have an appropriate level of expertise to confirm that it is of an acceptable scientific standard, however I have significant reservations, as outlined above.

\section{Author Response 15 Nov 2022}

\section{Abdullah Almojaibel}

\section{Dear reviewer,}

We would like to thank you for your valuable feedback.

We have modified the manuscript based on your suggestions. The introduction section is now modified with more literature about COVID-19 from KSA and other countries presenting the issues, and more statistics. All other valuable comments from the reviewer were also addressed/corrected in this version. Based on the additional citations, the reference list is now modified too.

Regards,

Competing Interests: No competing interest. 
The benefits of publishing with F1000Research:

- Your article is published within days, with no editorial bias

- You can publish traditional articles, null/negative results, case reports, data notes and more

- The peer review process is transparent and collaborative

- Your article is indexed in PubMed after passing peer review

- Dedicated customer support at every stage

For pre-submission enquiries, contact research@f1000.com 